Bundesgesundheitsbl 2019 $\cdot 62: 350$ https://doi.org/10.1007/s00103-019-02890-5 Online publiziert: 6. Februar 2019

(c) Springer-Verlag GmbH Deutschland, ein Teil von Springer Nature 2019

\title{
Dörte Ruhaltinger
}

Paul-Ehrlich-Institut, Langen, Deutschland

\section{Ausschreibung des Langener Wissenschaftspreises 2019}

Der Langener Wissenschaftspreis wird für hervorragende wissenschaftliche Arbeiten auf den folgenden Gebieten ausgeschrieben:

- der Infektiologie in der Human- und Veterinärmedizin

(zum Beispiel Virologie, Bakteriologie, Immunologie),

- der Erforschung von innovativen biomedizinischen Präventions- und Therapieansätzen,

- der Hämatologie,

- der Allergologie,

- der Gen- und Zelltherapie und des Tissue-Engineering,

- der Arzneimittelsicherheit und Pharmako-Epidemiologie

- sowie damit in Verbindung stehender technologischer Verfahren.

Der Langener Wissenschaftspreis ist mit $15.000 €$ dotiert und wird vom Verein zur Förderung des Langener Wissenschaftspreises e. V. gestiftet.

Nähere Informationen $z u$ den Ausschreibungsbedingungen und eine Liste der einzureichenden Bewerbungsunterlagen finden Sie unter www.pei.de/ langenerwissenschaftspreis bzw. unter www.langener-wissenschaftspreis.de.

Sowohl Einzel- als auch Gruppenbewerbungen sind möglich, wobei Bewerbungen von jüngeren Wissenschaftlern bevorzugt willkommen sind. Eine Altersgrenze wird jedoch nicht festgesetzt. Die Ausschreibung erfolgt deutschlandweit.

Die Bewerbungsunterlagen senden Sie bitte elektronisch an:

langener-wissenschaftspreis@pei.de.

Die Bewerbungsfrist endet am 31.05. 2019.

Unter den besten eingegangenen Bewerbungen wird die Preisträgerin/der Preisträger im Rahmen einer wissen- schaftlichen Vortragsveranstaltung im Herbst am Paul-Ehrlich-Institut ermittelt.

Die festliche Verleihung des Preises findet am 15.11.2019 ebenfalls am PaulEhrlich-Institut statt.

\section{Korrespondenzadresse}

Dörte Ruhaltinger

Paul-Ehrlich-Institut

Langen, Deutschland

langener-wissenschaftspreis@pei.de 